\title{
METAPROJETO - o design em busca da inovação por meio da reflexão
}

\author{
Kaori Ishihara Tamekuni \\ Universidade do Vale do Rio dos Sinos \\ kaoriishihara@uol.com.br
}

\begin{abstract}
Resumo: Este artigo visa fazer uma revisão de literatura sobre o conceito de metaprojeto. Abordar-se-ão as concepções de: Celaschi, Desserti, Manzini, Reyes, Moraes e Franzato. Ao analisar esses conceitos, pretende-se explorar que o metaprojeto não se diz apenas no projeto e sua metodologia, mas a uma forma de extrapolar o projeto, onde a elaboração de cenários dentro da perspectiva do metaprojeto auxiliará na concepção de um projeto mais inovador. Pretende-se apontar que o metaprojeto não se encontra como uma parte antecedente ao projeto, mas como um nível que acompanha o projeto antes, durante e após, em busca da já citada inovação.
\end{abstract}

Palavras-chave: Metaprojeto; inovação; design; cenários.

\section{Introdução}

O termo design, que ganhou força na era industrial, deve ser repensado, uma vez que design foi evoluindo juntamente com a sociedade. Não se deve mais associar o design apenas à indústria, à produção massificada. Mas o design inserido no contexto pós-moderno, onde a mercadoria passou a ter um novo valor, que vai além do monetário, e segundo Deserti (2007), "sobretudo, porque é a estrutura (troca de mercado da mercadoria) na qual se exprime a cultura contemporânea" (DESSERTI, 2007) se relaciona mais fortemente ao conceito de cultura de projeto. O Design que sai das esferas das soluções técnicas de processos industriais, e que se apropria de todo o processo de desenvolvimento das mercadorias contemporâneas.

Para dar conta desse novo papel, o projeto de design deve ser repensado. Nessa reformulação, apresenta-se o conceito de metaprojeto. Ao falar em metaprojeto, não se diz apenas sobre a metodologia do projeto, mas de todo um pensamento ligado ao projeto, que busca elevá-lo da categoria de design industrial para a cultura de projeto. Dentro desse posicionamento, utiliza-se a concepção de cenários que capacitará o designer para fornecer soluções inovadoras.

Esse artigo divide-se em quatro partes: na primeira parte, se fará a apresentação dos conceitos de design, sua evolução do produto industrial à mercadoria contemporânea. Na segunda parte, se fará uma análise dos conceitos de metaprojeto pelos seguintes autores: Celaschi, Deserti, Franzato, Reyes e De Moraes, como o capacitador do projeto de design para responder à necessidade de uma nova sociedade, fluida e dinâmica, onde a mercadoria contemporânea diz muito acerca das 
relações desta sociedade. Na terceira parte, serão apontados os cenários como um instrumento de alavancar a inovação dentro do metaprojeto. Na quarta parte, apresentará as considerações parciais, em que se retomará aos termos propostos e irá apontar um diagrama que tenciona auxiliar a compreensão do caráter retroalimentador do metaprojeto.

\section{Design}

O homem em seu processo de evolução desenvolveu diversos artefatos que lhe facilitaram a vida. Também a atividade de design, como construção de artefatos, remonta à pré-história, desde que os homens deram forma e função às pedras. Ao longo da evolução do design, podem-se destacar alguns momentos marcantes, como o Arts and Crafts, presente na primeira etapa da revolução industrial, em que o design procurou resgatar o traço do trabalho manual nas peças feitas pela indústria. Outro marco histórico situa-se no início do século $\mathrm{XX}$, em que o design tornou-se projeto industrial, e a fabricação esteve sob a tutela do funcionalismo. Nesta época, destaca-se a escola Bauhaus como referência do design, e ao fechar, deixou marcas em outras escolas de também de tradição racionalista e funcionalistas, como a ULM. Ser um artefato primeiramente funcional para então ser esteticamente agradável, era uma das premissas para ser um bom design (CARDOSO, 2008).

Através da definição do ICSID - International Council of Societies of Industrial Design - sobre design, pode se abrir o conceito do design para além da estética, da forma e da função. Ao dizer que: "Design é uma atividade criativa, que estabelece qualidades multifacetas aos objetos, processos, serviços e seus sistemas, em todo seu ciclo de vida" ${ }^{1}$ e ao detalhar sobre as tarefas, o ICSID relaciona design com o desenvolvimento de benefícios para a humanidade, a manutenção de culturas locais, melhoria da sustentabilidade, dar aos produtos, serviços, processos sentido (semióticos) e estéticos apropriados a sua complexidade.

Maldonado (1991) também desvincula o design industrial da concepção de que design se relaciona apenas à estética do produto ou que necessita da produção massificada e aponta para o caráter projetual, que terá fatores funcionais, simbólicos ou culturais alinhados a técnico-construtivos, técnico-sistêmicos, técnico-econômicos, técnico-distribuitivos. Além de se referir à não autonomia da atividade, ela é "condicionada pelo modo como a produção e o consumo de bens se manifestam numa determinada sociedade." (MALDONADO, 1991).

Apesar da evolução dos conceitos, ainda não se consegue ter uma dimensão do que é design, uma vez que design ultrapassou a barreira de projetos determinados pela forma e função, assim como também ultrapassou a era da produção industrial e massificada. Maldonado (1991) desvincula o design industrial da concepção de que ele se relaciona apenas à estética do produto ou à necessidade de produção massificada. Aponta, sim, para o caráter projetual e acrescenta fatores funcionais, simbólicos ou culturais alinhados a técnico-construtivos, técnico-sistêmicos, técnico-econômicos, técnico-distributivos ao projeto de design. Além de o autor referir a não autonomia da atividade, uma vez que ela é "condicionada pelo modo como a produção e o consumo de bens se manifestam numa determinada sociedade." (MALDONADO, 1991, p.14). $\mathrm{Na}$ sociedade contemporânea, fluida, complexa, imprevisível e instável (MANZINI,

\footnotetext{
${ }^{1}$ http://www.icsid.org/about/about/articles31.htm - acesso 06/05/2013. Tradução da autora.
} 
1990; MALDONADO, 1991; CARDOSO, 2008; MORAES, 2010), o design deve ir além do produto e integrar um conjunto, as pessoas aos produtos, de tal sorte que venha a proporcionar novas relações entre pessoas e objetos, e gerar, portanto, novos sentidos.

Já Flusser (2007) aponta os diversos significados semânticos que a palavra design traz, entre eles: propósito, meta, forma, estrutura básica, intenção, esquema maligno e conspiração, ligando o processo de design a traços de fraude e astúcia. Como verbo, destaca: tramar algo, simular, projetar, esquematizar, configurar, proceder de modo estratégico. A fraude que Flusser (2007) relaciona ao design, pode ser associada à capacidade do designer projetar para transformar, mudar algo unindo arte e técnica, com um determinado propósito.

Para Moraes (2009), design se situa como disciplina projetual de produtos, bens, serviços, além de ser um transformador nos âmbitos tecnológicos, sociais e humanos.

Franzato (2010) atenta para um novo posicionamento do design, ao não se ater mais, apenas, à produção industrial massificada. 0 design passa a incorporar projetos de edições limitadas ou até mesmo de uma única peça. Isso cria uma aproximação com a empresa contemporânea e abre novas possibilidades de aplicação do design. Franzato, neste mesmo texto, ainda, explora a capacidade de denotar de produção de sentido do design: "o aprimoramento da sua capacidade de agregar valores semânticos aos objetos e de tomar consciência das suas possibilidades comunicativas." (FRANZATO, 2010)

\section{Design, sociedade e mercadoria contemporânea.}

Assim como Maldonado (1991), Celaschi (2007) explora o papel do design sob uma perspectiva de mercado, uma vez que Celaschi diz que uma sociedade que pode ser analisada a partir de seu consumo e o design é o mediador capaz em conduzir a escolhas de determinadas mercadorias.

Para Celaschi, o mercado é o reflexo da cultura, uma vez que as pessoas estão sempre atuando nele, seja ao consumir ou ao vender algo. Celaschi explora a capacidade do Design em articular: viabilidade técnica e vantagem econômica (valor de troca), significados (valor relacional) e usabilidade e sustentabilidade (valor de uso), dentro da cadeia de valor. A habilidade do design em solucionar problemas, de se relacionar com os desejos da empresa e de seu cliente final, tornaram-no um mediador, uma vez que os desejos de ambos não costumam estar alinhados. Para resolver tais questões caberá ao designer considerar e interpretar as exigências do mercado e a cadeia de valor em que empresa e consumidor se inserem.

Segundo Celaschi (2007), para compreender e atuar sobre a cadeia é necessária a articulação de diversas áreas, cabendo ao designer o papel deste articulador, posto que pode se considerar o design como a cultura de projeto seja como principal agente do processo de troca ou como contribuições pontuais em processos dirigidos por outras áreas.

A cadeia de valor é uma ação multidisciplinar que necessita de muitas contribuições de operadores pertencentes a disciplinas diversas e, frequentemente, concorrentes profissionalmente entre si. Neste texto desejamos focar a nossa atenção sobre a contribuição que a cultura de projeto (frequentemente representada apenas pelo termo "design") tem condições de oferecer para a cadeia de valor, seja em termos de contribuição local e pontual dentro de processos governados por outros 
conhecimentos, seja em termos de comando do processo. (CELASCHI, 2007, p.16)

Além da cadeia de valor, deve ser considerar que os produtos se tornam mais parecidos em um menor tempo. A logística de distribuição se aprimora cada vez mais, tornando-se possível adquirir produtos que em outras épocas foram considerados vindos de partes longínquas do mundo. O design assume o papel de torná-los de mercadorias e bens de consumos indistinguíveis em mercadorias contemporâneas, através do que Celaschi (2007) define por sua

"capacidade de estarem no mercado e serem escolhidos pelos consumidores em uma situação de forte concorrência. (...) cuja forma muito sofisticada é somente objeto de uma atenta avaliação, idealização, programação, projetação, realização, comunicação e distribuição". (CELASCHI, 2007, p.16)

Franzato (2010) cita a permeabilidade da mercadoria contemporânea, a saturação do mercado e a capacidade das mercadorias, dos produtos e serviços ofertados pelas empresas de se conectar a determinados grupos, criando subculturas, enquanto Deserti (2007) ressalta o design como potencializador da formação dos valores da mercadoria contemporânea.

Diante da mercadoria contemporânea, o design como cultura de projeto, assume papel de maior relevância, uma vez de acordo com Celaschi, (2007) o que muda com maior frequência é a forma de pensar do homem, sobre si, sobre a sociedade, e assim muda seus símbolos e modos de se relacionar através das mercadorias.

\section{Metaprojeto}

Se não se deve mais associar o design apenas à indústria, à produção massificada, também deve se repensar sobre a concepção do projeto de design. 0 projeto de design deverá ser capaz de compreender a mercadoria contemporânea, os elos da cadeia de valor, o cliente final e o cliente que solicita o projeto. Sob essa necessidade de conceituação do novo projeto, cunhou-se o termo metaprojeto.

Deserti (2007) apresenta o metaprojeto como a aptidão em unir ao projeto: o talento de explanar e avaliar as relações contextuais à inclinação de conceber oportunidades que contenham em si inovações potenciais à análise de contexto e o gerar projetos inovadores. O metaprojeto se constitui desde a fase de pesquisa ao concept design, a conceituação do projeto, e é apontado por Deserti (2007) como o processo capaz de promover a inovação, não estando necessariamente atrelado ao processo executivo do projeto, mas sim, ao processo de ideação através da pesquisa e desenvolvimento.

Metaprojeto, por Celaschi (2007), é a ideação e organização do processo de pesquisa e de projeto. Também chamado por ele de "projeto do projeto", ele se constituirá de fases, tempos e recursos financeiros e de pessoal, tudo com vistas à inovação.

"A esse saber acrescentamos o estudo dos problemas que aparecem na dimensão metaprojetual do processo de inovação, ou seja, a dimensão que prepara e consolida o saber do projetista para levá-lo a mover-se com desenvoltura nos mecanismos que regulam os fluxos de valores, as dinâmicas de negócio no mercado, o dimensionamento e a caracterização 
dos desempenhos (também não tangíveis) das mercadorias." (CELASCHI, 2007)

Como capacidades do metaprojeto, Celaschi (2007) aponta: a pesquisa prévia, que seja capaz de trazer informações relevantes para o projeto, porém que não cerceiem a capacidade do designer de ir além do projeto; e organizar modificar, modelar, adaptar o processo e suas fases, para torná-lo apto para cumprir seus objetivos. O metaprojeto também permite aos gestores da organização perceber quão complexo é um processo inovador e que o mesmo necessita do envolvimento de toda a empresa, criando uma cultura metaprojetual.

Para Franzato (2011) o metaprojeto tem o caráter transdisciplinar e não se atém a uma determinada fase ou etapa do projeto, mas poderá perpassar por todo o projeto, onde a pesquisa e o projeto se mesclarão. O metaprojeto visto por Franzato (2011, 2012), possibilita o desenvolvimento de projetos inovadores. O resultado de maior relevância do metaprojeto não é o produto inovador em si, mas a criação da cultura de projeto metaprojetual dentro da organização.

Moraes aborda a complexidade do mundo contemporâneo como o gatilho de uma nova forma de projetar do design. Se o produto imprime uma marca em seu usuário, o design ultrapassa o objeto em si. Assim percebe-se que o projeto do produto não termina com sua produção, mas continua junto ao seu uso. Moraes (2009) propõe então que para se lidar com a inserção de valores intangíveis, a construção de sentidos se utilize uma visão mais abrangente, que não permeie apenas o produto, mas que consiga analisar o contexto em que o produto se insere. Para se atingir esse objetivo, ele traz ao metaprojeto o caráter não linear, em constante feedback e cita o cenário como a fase que firma o metaprojeto, auxiliando na geração de concepts. Moraes trata o metaprojeto por modelo projetual, que compreende o projeto do início ao fim, que potencializa a metodologia convencional, ao não apresentar o caráter linear que engessava a criatividade e desenvolvimento dentro da "velha metodologia". A concepção de metaprojeto de Moraes consta a pesquisa prévia, a ênfase na produção de sentido, na relação entre usuário e produto, no que isso acarreta e na construção de cenários. Ele situa-se como espaço para a reflexão e colaboração para os conteúdos da pesquisa projetual anterior à fase projetual, o próprio projeto.

Após os conceitos acima apresentados é possível indicar, algumas características que constituem o metaprojeto. A começar pela formação da equipe de projeto, composta por múltiplos atores oriundos de diversas áreas. Essa composição trará pontos de vista diversos, que poderão enriquecer o projeto. Como outra característica do metaprojeto, percebe-se a pesquisa prévia, que seja capaz de trazer informações relevantes para o projeto. Porém essa pesquisa não deverá cercear a capacidade do designer de ir além do projeto. A pesquisa servirá para a reflexão a cerca do projeto, mas que não o engesse, nem leve a um resultado direcionado por uma solução pontual. O próprio modo de organizar os processos do projeto, sob o metaprojeto, aponta para seu caráter reflexivo. Esse modo não segue um único caminho, préformatado, mas será direcionado pela necessidade do projeto, que irá indicar quais ferramentas deverão ser usadas durante o processo de projeto. Essas poderão, inclusive serem modificadas, modeladas e adaptadas, para tornar o processo de projeto apto a cumprir seus objetivos. Além de que a não restrição à determinada fase ou etapa do projeto ser o espaço onde a pesquisa e o projeto se mesclarão, dentro da 
perspectiva reflexiva do metaprojeto, e irá orientar as ações que perpassarão o todo o projeto. Acredita-se que essas características agreguem ao projeto um maior potencial de inovação. A própria complexidade desse tipo de processo ao ser percebida pelos gestores das organizações, deverá promover o envolvimento de toda a empresa, criando um cultura metaprojetual. (CELASCHI, 2007, DESSERTI, 2007; FRANZATO, 2012, 2011; MORAES, 2009).

Ao falar de metaprojeto, sugere-se a colocação do mesmo como um nível, ao não abordá-lo como fase ou etapa, retira-se dele o caráter temporal hierárquico, e ao considerá-lo como nível, ele poderá se posicionar ao lado do projeto ou como um nível que entremeia outro.

\section{Cenários}

Se metaprojeto se relaciona fortemente à inovação, para que ela seja alavancada, diversos autores propõe o uso de cenários. Para Manzini e Jegóu, (2004), a construção de cenários é um aporte para tomada de decisões. Através dos cenários podem-se abordar diversas possibilidades de contexto, onde a reflexão sobre a decisão se torna mais clara. Para Manzini e Jegóu, (2004), por exemplo, a construção de cenários é um aporte para a tomada de decisões. Através dos cenários, é possível identificar diversas possibilidades de contexto, além de favorecer a clareza na tomada de decisão. A participação de diversos atores na elaboração dos cenários, aumentam a capacidade de gerar e de articular ideias. O cenário, tal como os autores acima compreendem, não é um exercício advinhatório, pelo contrário, se baseará em coleta e análise de informações que servirão de base para as propostas de cenário. Para a construção de cenários, Manzini e Jegóu apontam-se três componentes essenciais, sendo o primeiro a visão, que propõem contextualização, através de história, sobre determinado evento, "como seria o mundo se...". O segundo componente é a motivação, em que se pergunta sobre a relevância do cenário, "por que esse cenário é significativo?". O terceiro componente é a proposta, momento em que se legitima o cenário, "como é articulada concretamente a visão? Quais são seus elementos? Como se pode implementá-la?..." (MANZINI e JEGÓU, 2004, p.192).

Cenário pode ser visto como um processo fluido, que permite a reflexão sobre o futuro, mas que pode ser alimentado a partir de outras informações e análises de contexto; o metaprojeto, por outro lado, "configura-se como uma plataforma de conhecimentos, que serve para a tomada de decisões em cenários futuros de natureza incerta, dinâmica e fluida" (REYS, 2012, p.93). Como já referido, para Moraes (2010) a elaboração de cenário é a consolidação do metaprojeto. É uma forma proposta para se conhecer e refletir sobre a realidade atual ou futura e que dará ao designer condições de "traçar limites, analisar e, sobretudo realizar uma síntese compreensível de cada etapa projetual já por ele superada” (p.21).

Cenários para Deserti (2007) são vistos como potencializadores da inovação dentro do metaprojeto. Ele cita o caráter, de estimular a criatividade, próprio dos cenários, uma vez que se conjugam os dados da pesquisa, referentes aos comportamentos das pessoas e de grupos sociais, para a construção de cenários antagônicos, que poderão encorajar ou direcionar ao concept design. Esse autor também chama o mapa de inovação de cenário, pois, em conjunto, trarão os sinais fortes e fracos da análise de contexto. 
Outro autor que associa cenários a inovação é Franzato (2011). Ele situa a origem dos cenários nas estratégias militares que foram assimilados pelas empresas, para tentar prever em que contexto se encontraria o mercado, a logo prazo. Ao trazer o cenário com a perspectiva de inovação para o design, como parte do metaprojeto, destaca a possibilidade de usar os cenários como peças fundamentais para clarear 0 projeto, uma vez que entre o concept e o cenário há uma relação intrínseca. Ressaltase o caráter de catalisador de concept design, de resignificação e de inovação no enquadramento dos cenários como reflexão metaprojetual.

\section{Considerações parciais}

Design, em uma sociedade dinâmica, pós-industrial, deve se reposicionar e mostrar que não é apenas o projeto de coisas, mas um projeto que integrará pessoas e artefatos, mercadorias. Assim a mercadoria contemporânea é um produto que traduz a relação entre o homem, cultura e sociedade. Percebe-se que o objeto, que até então era a principal preocupação do designer, passa a ser secundário perante a complexa rede de relacionamentos que deverá ser levada em consideração. Onde esse usuário está inserido, como ele se relaciona com seus pares, quais são os aspectos da sua sociedade e o valor que o produto terá para ele devem ser considerados no novo cenário do design. Assim poderá se considerar design, também, como o que visa criar o sentido, as relações com o que é projetado em uma sociedade complexa.

Para que possa se elaborar projetos que tragam uma renovação no sentido, que tenham em si a inovação é preciso repensar em como se projetar, e para isso o metaprojeto se apresenta como uma profunda reflexão sobre o projeto. 0 metaprojeto não é composto de uma única característica, vem como uma reposta a uma sociedade dinâmica, fluida e desta forma também deve ser dinâmico e fluido. Por seu caráter reflexivo, o metaprojeto é mais que metodologias, mas tem que se considerar que há uma característica metodológica determinante ao metaprojeto: o analisar constante do projeto, sua retroalimentação, as retomadas em todas suas fases: pré-projetual; durante o projeto; e após o projeto, com o intuito de aprimorar o projeto. 


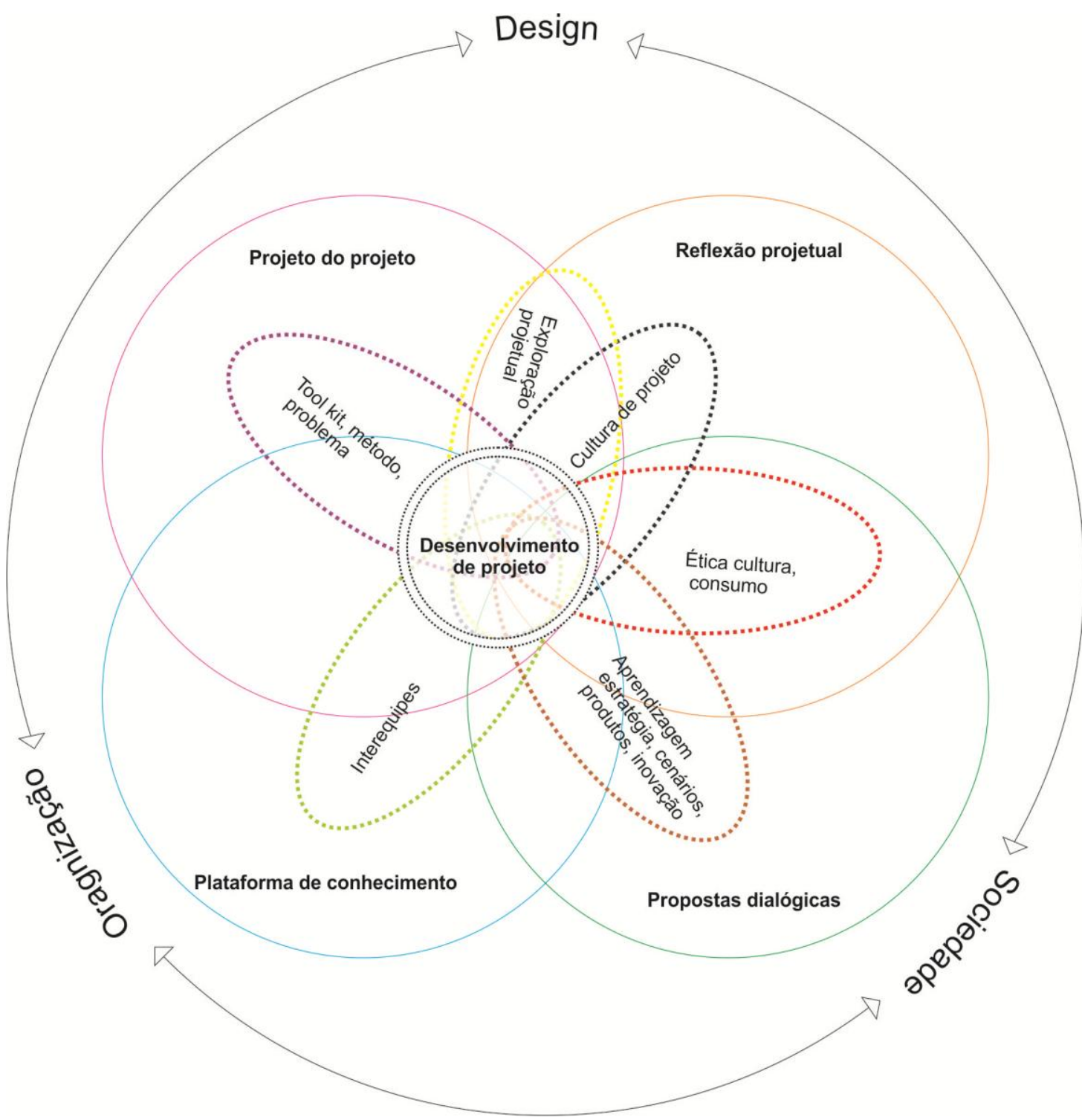

Figura 1. Metaprojeto e seu caráter transdisciplinar e retroalimentador.

Fonte: autoria própria

Essa característica de voltar e rever as várias fases do projeto, de interagir com diversas áreas de conhecimento, aumentam a potencialidade de inovação do projeto, faz com que o designer tenha maiores conhecimentos sobre a organização, sobre o produto, sobre o usuário a que ele destina, a sociedade e cultura da qual ele faz parte, sobre o armazenamento, a divulgação e a comunicação. Além de incentivar a efetiva participação do corpo diretivo da empresa ao longo do metaprojeto, que podem resultar à empresa na possibilidade de incorporar a cultura de metaprojeto e consequentemente a cultura da inovação em seu cerne. Considera-se então metaprojeto toda a reflexão a cerca do projeto e se propõe como exercício futuro uma reflexão sobre como alinhar a semiótica de Peirce, a abdução, no processo metaprojetual, na construção do concept design.

\section{Referências}

CARDOSO, R. Uma introdução à história do design. São Paulo: Blücher, 2008. 
CELASCHI, F. Dentro al progetto: appunti di merceologia contemporanea. In: CELASCHI, F.; DESERTI, A. Design e innovazione: strumenti e pratiche per la ricerca applicata. Roma: Carocci Editore, 2007, pp. 15-56.

DESERTI, A. Intorno al progetto: concretizzare l'innovazione. In: CELASCHI, F.; DESERTI, A. Design e innovazione: strumenti e pratiche per la ricerca applicata.Roma: Carocci Editore, 2007, pp. 57-121.

FLUSSER, V. O mundo codificado. Por uma filosofia do design e da comunicação. 1a ed. São Paulo: Cosac Naify, 2007.

FRANZATO, C. O processo de inovação dirigida pelo design. Um modelo teórico. Redige, v. 2, n. 1, 2011, p. 50-62. Disponível em:

http://www.cetiqt.senai.br/ead/redige/index.php/redige/article/viewArticle/72

FRANZATO, C.; CELASCHI, F. Processo de metaprojeto para o desenvolvimento estratégico e a inovação das organizações. In: X P\&D Design - Congresso Brasileiro de Pesquisa e Desenvolvimento em Design, 2012, São Luís. Anais do X Congresso Brasileiro de Pesquisa e Desenvolvimento em Design. São Luís: EDUFMA, 2012. p. 1-14. Disponível em:

http://www.academia.edu/2510981/Processo_de_metaprojeto_para_o_desenvolvime nto_estrategico_e_a_inovacao_das_organizacoes

MALDONADO, T. Design Industrial. Lisboa: Edições 70. 1999

MANZINI, E.; JÉGOU, F. Design dos cenários. In: BERTOLA, P.; MANZINI, E. Design Multiverso | Notas de fenomenologia do design. Milano: Edizioni POLI.design, 2006, pp. 189-207.

MORAES, D. Metaprojeto: o design do design. São Paulo: Blücher, 2010. Cap. 2, 3 e Conclusões

REYES, P. Projetando pela exterioridade do projeto. Strategic Design Research Journal, v. 5, n. 2, 2012, p. 91-97. Disponível em:

http://www.unisinos.br/_diversos/revistas/ojs/index.php/sdrj/article/view/sdrj.2012.5 2.05 